\title{
KETERKAITAN USIA, JENIS KELAMIN, DAN TINGKAT RELIGUITAS TERHADAP PENERAPAN GAYA KEPEMIMPINAN
}

\author{
Widhi Ariestianti R \\ widhiariestianti@stiesia.ac.id \\ Program Studi Manajemen \\ STIESIA Surabaya
}

\begin{abstract}
:
The purpose of this study to analyze the influence of age, sex and religiousity on leadership style. Dependen variabel in this research is leadership style and independen variabel in this research are sex, age and religiousity. The samplein this study are worker who have subordinate to do dialy job. The method use is the multiple linier analysis regresion. The result of thi study indicate that age, sex and religousity have direct influence on leadership style. Age has dominan influence on leadership style, and than religiousty has secound dominan influence on leadership style. Sex has little influence on leadership style. From this analysis can be know that whatever gander of leader as long as more spiritual experince, more mature person is shown by life experince they owen, they will more wise in applying leadersip style. Leader will support their subordinate for improve their self potential.
\end{abstract}

Keywords : Age, Gender, Religiousity, Leadership Style

\section{PENDAHULUAN}

Sebagai salah satu sekolah tinggi yang cukup lama berdiri di surabaya, Sekolah Tinggi Ilmu Ekonomi Surabaya merupakan perguruan tinggi yang mampu bertahan dan bersaing dengan perguruan tinggi yang ada. Selain itu, Sekolah Tinggi Ilmu Ekonomi Surabaya juga mampu menyesuaikan diri dengan perubahan serta perkembangan jaman yang terus berkembang secara dinamis. Hal ini dapat dilihat dari perkembangan yang dicapai sampai saat ini.

Perkembangan yang dicapai saat ini tentunya tidak terlepas dari peran pemimpin dalam memimpin selama ini. Perumusan strategi pembangunan dan pengembangan suatu organiasasi merupakan salah satu tugas dari pemimpin. Tidak semua orang dapat menjadi pemimpin, hal ini dikarenakan pemimpin merupakan seseorang yang dapat mempengaruhi dan mengarahkan sekelompok orang dalam suatu organisasi dalam mencapai tujuannya.

Cara pemimpin dalam memimpin organisasi dapat dilihat dari gaya yang diterapkan. Terdapat berbagai macam jenis gaya kepemimpinan, salah satu gaya kepemimpinan yang banyak dirujuk adalah gaya kepemimpinan yang dikembangkan oleh Bass dan Avolio (1994) yaitu gaya kepemimpinan transformasional, transaksional dan laissezfaire. Masingmasing gaya kepemimpinan memiliki pendekatan yang berbeda dalam mengambil setiap keputusan.

Kotur dan Anbazhagan (2014) jenis kelamin dan tingkat usia mempengaruhi gaya kepemimpinan pekerja. Pemimpin pada usia midle age yaitu usia 35 - 45 tahu lebih autrokratis dalam memimpin, seiring dengan 
berjalannya waktu usia pemimpin diatas 46 tahun akan lebih demokratis. Semakin lanjut usia pemimpin maka semakin cenderung pemimpin kurang peduli terhadap karyawan. Sesuai penjelasan diatas dapat disimpulkan bahwa usia seorang pemimpin mempengaruhi gaya kepemimpinan yang diterapkan dalam kesehariannya. Felix, et al ( 2015) Tingkat religuitas memiliki pengaruh terhadap gaya kepemimpinan transformasional serta vertical individualism dan religousity secara signifikan dapat memoderasi keterkaitan antara gaya kepemimpinan transformasional dan post conventional reasoning.

Hage (2013) tingkat religuitas memiliki keterkaitan sedikit atau hampir tidak memiliki keterkaitan terhadap praktek kepemimpinan yang dijalankan oleh pemimpin. Namun pemimpin dengan agama Kristen ditemukan bahwa terdapat sedikit dan signifikan keterkaitan antara tingkat religuitas dan gaya kepemimpian. Pemimpin yang bergama Islam ditemukan tingkat religuitas tidak memainkan peran yang signifikan terhadap gaya kepemimpinan. Berdasarkan penjelasan diatas, dapat disimpulkan terdapat keterkaitan antara tingkat religuitas dengan gaya kepimpinan pemimpin.

Berdasarkan pemaparan diatas, penelitian ini ingin mengetahui apakah terdapat keterkaitan antara faktor usia, jenis kelamin dan gaya kepemimpinan memiliki pengaruh terhadap penerapan gaya kepemimpinan transformasional yang diterapkan di STIE Surabaya. Dari hasil penelitian yang ada, dimensi apa pada tingkat religuitas yang mendominasi pengaruh gaya kepemimpinan transformasional yang diterapkan. Pada gaya kepemimpinan yang diterapkan, dimensi apa yang memiliki pengaruh paling dominan.

\section{LANDASAN TEORI}

\section{Gaya Kepemimpinan} Transformasional

Setiap gaya kepemimpinan memiliki karakteristik yang berbeda. Akar (2010) gaya kepemimpinan transformasional lebih menekankan pada pendekatan secara personal. Pemimpin dengan gaya kepemimpinan tranformasional dicirikan dengan pemimpim membantu karyawan dalam menyadari sesuatu yang penting dan mengembangkan potensi yang dimiliki karyawan, dan selalu melihat peluang dan tantangan yang dihadapi dengan cara pandang lain yang lebih baru.

Robbins dan Judge (2008) terdapt karakteristik dari gaya kepemimpinan transformasional yaitu :

- Pengaruh yang ideal: pemimpin menyampaikan visi dan misi kepada sub ordinat; menanamkan kebanggan pada diri sub ordinat akan dirinya sendiri, organisasi dan pemimpin; pemimpin mendapatkan rasa hormat dan kepercayaan dari sub ordinat.

- Motivasi inspirasional: pemimpin dapat mengkomunikasikan harapan yang tinggi pada sub ordinat dengan baik pemimpin menggunakan simbol untuk berfokus pada usaha yang dilakukan oleh sub ordinat, pemimpin mampu menyampaikan tujuan yang ingin dicapai dengan bahasa sederhana dan dimengerti.

- Pertimbangan individual: pemimpin memberikan perhatian pribadi kepada sub ordinat, mampu memperlakukan sub ordinat secara individual, mampu memberikan pelatihan dan saran mudah dimengerti oleh sub ordinat.

Bass (1997) terdapat empat dimensi yang menggambarkan gaya kepemimpinan transformasional yaitu (i) Idealize influence.Pemimpin merupakan seseorang yang disegani, dihormati dan menjadi inspirasi bagi 
para karyawannya. Pemimpin juga merupakan role model bagi para karyawan (Sultan,et al; 2015) dan pemimpin memberikan contoh bagaimana peran pemimpin bagi karyawan (Akar, 2010). (ii) Intelectual stimulation.

Pada dimensi ini dijelaskan juga bahwa pemimpin akan memberikan tantangan, peraturan, misi, serta mengajarkan karyawan untuk mengambil resiko, memberikan kesempatan kepada karyawan menghadapi berbagai kemungkinan yang dapat terjadi serta memberikan ruang bagi karyawan untuk mengembangkan pemikirannya (Sultan, et al, 2015).(iii)Individual consideration.

\section{Tingkat Religuitas}

Tingkat religuitas menggambarkan seberapa jauh dan dalam seseorang atas keimanannya. Tingkat religuitas suatu komitmen terhadap perilaku religi, pelaksanaan, keyakinan, ekspresi dan motivasi (Hage, 2013). Holdcroft (2006) religuitas terdiri atas berbagai aspek dan hal ini berkaitan dengan istilah iman, kepercayaan, kesalehan, ortodoks, tingkat keimanan dan pengabdian. Huber dan Huber (2012) terdapat lima dimensi dalam mengukur tingkat religuitas yaitu :

\section{a. Public Practice}

Kehidupan sosial seseorang yang religius biasanya aktif dalam kegiatan religius di komunitas mereka. Kegiatan religius merupakan partisipasi masyarakat dalam ritual keagamaan dan kegiatan komunitas. (Huber dan Huber,2012).

\section{b. Private Practice}

Seseorang yang religius akan menyerahkan atau mendedikasikan dirinya pada Tuhan dalam aktivitas kehidupan pribadi mereka. Pada sisi individu dimensi ini digambarkan sebagai pola perilaku individu dalam menyerahkan diri kepada Tuhan. (Huber dan Huber, 2012).

\section{c. Religious Experince}

Sesorang yang religius biasanya mempunyai kontak secara langsung dengan Tuhan, hal ini mempengaruhi emosi mereka. Pada sisi individual, dimensi ini digambarkan pola persepsi atau pandangan religius digambarkan dalam bentuk pengalaman dan perasaan religius yang dialami oleh seseorang (Huber dan Huber, 2012).

\section{d. Ideology}

Secara sosial, seorang individu yang religius memiliki keyakinan akan keberadaan dan esensi keberadaan transenden serta hubungan antara sesuatu yang tersenden dengan manusia. Pada sisi individual, dimensi ini menggambarkan keyakinan, serta pola masuk akal yang tidak diragukan lagi (Huber dan Huber,2012).

\section{e. Intelectual}

Secara sosiologis, dimensi ini menggambarkan pandangan sosial orang-orang religius memiliki pengetahuan agama yang lebih baik, dan orang yang religius dapat menjelaskan pandangannya mengenai tarnsendan, agama dan religuitas. Pada dimensi ini, dari sudut pandang individu, gambar ketertarikan mereka, sudut pandang dalam berfikir dan interpretasi serta pondasi pengetahuan yang dimilikinya (Huber dan Huber, 2012).

\section{Hipotesis}

Berdasarkan pendahuluan diatas dapat di rumuskan hipotesis sebagai berikut: H1=Terdapat keterkaitan yang cukup kecil antara tingkat religuitas dengan gaya kepemimpinan.

$\mathrm{H} 2=$ Terdapat keterkaitan antara usia pemimpin dengan gaya kepemimpinan 
H3=Terdapat keterkaitan antara jenis kelamin dengan gaya kepemimpinan

\section{METODE PENELITIAN}

Jenis penelitian ini adalah penelitian deskripsi. Metode diskriptif menerangkan hubungan, menguji hipotesis - hipotesis, membuat prediksi serta mendapatkan makna dan implikasi dari suatu masalah yang ingin dipecahkan (Nazir, 2013). Data yang digunakan dalam penelitian ini adalah data primer yang didapatkan melalui penyebaran kuesioner. Responden dalam penelitian ini adalah karyawan STIESIA Surabaya yang memiliki sub ordinat dalam menjalankan aktivitas pekerjaan sehari - hari. Sampel penelitian ini sebesar 80 responden dan kuesioner yang layak digunakan hanya 75 orang.

\section{Teknik Analisis Data}

Regresi linier berganda digunakan dalam penelitian ini dikarenakan ingin mengetahui hubungan antara variabel dependen dengan variabel independen. Model estimasi yang digunakan untuk membentuk persamaan regresi adalah metode ordinary least square. Adapun persamaan dalam penelitian ini adalah$$
\mathrm{GPT}=\alpha+\beta \mathrm{TR}+\beta \mathrm{U}+\beta \mathrm{JK}+\mu
$$

Dimana TR merupakan tingkat religuitas, $\mathrm{U}$ adalah usia dan $\mathrm{JK}$ merupakan jenis kelamin. Sebelum uji asumsi klasik terlebih dahulu dilakukan (1) uji validitas dan reabilitas guna menjamin bahwa alat pengukur yang digunakan valid dan realibel. Agar hasil yang didapatkan dapat digunakan sebagai estimator, maka model harus memenuhi syarat yaitu BLUE (Best, Linear, Unbiased, Estimated). Guna memenuhi syarat BLUE, maka model harus lulus uji asumsi klasik. (3) Uji asumsi klasik yaitu uji multikolinearitas, dan uji heteroskidasitas. Uji autokorelasi tidak dilakukan karena data yang digunakan tidak berurutan sepanjang waktu. (4) Uji Hipotesis. Uji ini dilakukan uji $F$ yaitu uji model regresi guna melihat pengaruh variabel independen secara bersama terhadap variabel dependen. Uji $t$ guna mengetahui pengaruh masing-masing variabel independen terhadap variabel dependen.

Koefisien Determinasi $\left(\mathbf{R}^{2}\right)$, Uji ini untuk melihat seberapa jauh suatu model mampu menerangkan variasi variabel dependen. Nilai koefisien determinasi adalah antara nol dan satu. Jika $\mathrm{R}^{2}$ kecil maka kemampuan variabel independen dalam menjelaskan variabel dependen amat terbatas.

\section{Definisi Operasional}

1.Gaya kepemimpinan trasnformasional yang diterapkan di STIESIA Surabaya.Pengukuran gaya kepemimpinan transformasional menggunakan pendekatan 4 dimensi oleh Bass dan Avolio (1992) yaitu idealized influence, inspirational motivation, intelectual stimulation dan individual consideration.

2. Tingkat religuitas menggambarkan seberapa dalam tingkat keimanan dalam kehidupan sehari-hari. Tingkat keimanan dapat dilihat dari tingkat partisipasi dalam aktivitas keagamaan sehari-hari. Pengukuran tingkat religuitas ini menggunakan pendekatan the centrality of religion scale (CRS) yang dikembangkan oleh Huber dan Huber (2012) dengan menggunakan pendekatah lima dimensi yaitu dimensi public practice, privat practice, religious experince, ideology dan intelectual.

3.Usia dan jenis kelamin. Usia sebagai usia responden pada saat mengisi kuesioner dan Jenis kelamin responden penelitian. 
HASIL DAN PEMBAHASAN

\section{Gambaran Umum Objek Penelitian}

Tabel 1

Deskriptif Variabel Jenis Kelamin

\begin{tabular}{|c|c|c|}
\hline Jenis Kelamin & Frekwensi & Persentase \\
\hline Pria & 40 & $53,3 \%$ \\
\hline Wanita & 35 & $46,7 \%$ \\
\hline Jumlah Frekwensi & 75 & \\
\hline
\end{tabular}

Sumber : Data Primer, diolah 2018

Berdasarkan Tabel 1 diketahui Responden wanita sebanyak 35 orang mayoritas responden penelitian ini atau 46,7\% dari total responden. Dari adalah laki-laki sebanyak 40 orang segi usia responden dapat dijelaskan atau 53,3\% dari total reponden. pada Tabel 2 dibawah:

Tabel 2

Deskriptif Variabel Usia

\begin{tabular}{|c|c|c|}
\hline Jenis Kelamin & Frekwensi & Persentase \\
\hline $29-30$ thn & 7 & $9,3 \%$ \\
\hline $31-40$ thn & 16 & $21,3 \%$ \\
\hline $41-50$ thn & 16 & $21,3 \%$ \\
\hline $51-60$ thn & 32 & $42,7 \%$ \\
\hline Usia > 60 thn & 4 & $5,3 \%$ \\
\hline Jumlah & 75 & \\
\hline
\end{tabular}

Sumber : Data Primer, diolah 2018

Berdasarkan Tabel 2 dapat diketahui bahwa banyak responden berusia antara 51-60 Tahun sebanyak 32 responden atau $42,7 \%$ dari total reponden. Responden yang berusia $31-$ 40 tahun dan $41-50$ tahun terdiri dari
16 responden atau $21,3 \%$ dari total reponden. Usia 29-30 tahun 7 responden atau $9,3 \%$ dari total responden dan terdapat 4 reponden berusia diatas 60 tahun atau sebesar $5,3 \%$ dari total responden.

\section{Statistik Deskriptif Penelitian}

Tabel 3

Statistik Deskriptif Variabel Tingkat Religuitas

\begin{tabular}{|l|c|}
\hline \multicolumn{1}{|c|}{ Dimensi } & Nilai Rata - Rata Dimensi \\
\hline Dimensi Intellect & 3,72 \\
\hline Dimensi Ideology & 3,91 \\
\hline Dimensi Public Practice & 3,61 \\
\hline Dimensi Private Practice & 4,25 \\
\hline Dimensi Experience & 4,43 \\
\hline
\end{tabular}

Berdasarkan Tabel 3 diketahui bahwa dimensi yang mendominasi adalah dimensi religious experince, Dimensi ini menggambarkan bahwa seseorang yang religius kontak langsung dengan Tuhan dan dapat mempengaruhi secara emosi. Dimensi ini menggambarkan pola persepsi, perasaan dan pengalaman religius yang mengaitkan dirinya dengan Tuhan. Pertanyaan yang memiliki nilai tertinggi bahwa terkadang kita merasakan bahwa
Tuhan ingin menyampaikan atau berkomunikasi kepada diri kita. Hal ini biasanya kita rasakan saat kita berdo'a kepada Tuhan. Saat kita berdoa dapat merasa seperti berkomunikasi dengan Tuhan. Terdapat suatu perasaan saat menghadapai permasalahan atau tidak dan kita merasakan suatu perasaan yang berbeda seperti lebih tenang, lebih lega, dan lebih nyaman. Apapun yang dilakukan ketika diawali dengan do'a akan memberi hasil yang terbaik. 
Tabel 4

Statistik Deskriptif Variabel Gaya Kepemimpinan Transformasional

\begin{tabular}{|l|c|}
\hline \multicolumn{1}{|c|}{ Dimensi } & Nilai Rata-Rata Dimensi \\
\hline Dimensi Idealize Influence & 3,79 \\
\hline Dimensi Inspirational Motivation & 3,95 \\
\hline Dimensi Intellectual Stimulation & 3,84 \\
\hline Dimensi Individual Condisertaion & 3,88 \\
\hline
\end{tabular}

Berdasarkan Tabel 4 dimensi dominan pada gaya kepemimpinan transformasional adalah inspirational motivation. Dimensi ini menjelaskan pemimpin selalu mengkomunikasikan tujuan, visi misi kepada sub ordinat dan mengajak ikut dalam mewujudkannya. Guna mewujudkan visi dan misi tersebut pemimpin berusaha untuk meningkatkan kepedulian sub ordinat terhadap visi dan misi organisasi serta menyakinkan sub ordinat bahwa mereka mampu mencapai visi dan misi organisasi. Dari tiga pertanyaan yang menyusun dimensi ini, pertanyaan yang memiliki nilai terbesar ialah pemimpin membantu para sub ordinat memahami pentingnya pekerjaan mereka. Jika mereka memahaminya, maka mereka akan bekerja dengan semangat dan bangga karena mereka mengetahui apa yang dilakukan memiliki kontribusi bagi organisasi dalam mewujudkan tujuannya.

\section{Uji Validitas}

\section{Tingkat Religuitas}

Variabel tingkat religiutas diukur dengan 5 (lima) dimensi dan terdiri dari 15 pertanyan, untuk dimensi intellect yang terdiri dari 3 pertanyaan, dimensi ideology terdiri dari 3 pertanyaan, dimensi public practice terdiri dari 3 pertanyaan, dimensi private practice terdiri dari 3 pertanyaan, dan dimensi experience terdiri dari 3 pertanyaan, Berikut hasil uji validitas variabel tingkat religuitas, seperti Tabel 5:

Tabel 5

Hasil Uji Validitas Tingkat Religuitas

\begin{tabular}{|c|c|c|c|}
\hline Dimensi & $\begin{array}{c}\text { Nilai Koefisien Korelasi } \\
\text { Product Moment }\end{array}$ & $\begin{array}{c}\text { Nilai Koefisien Korelasi Product Moment } \\
\text { Tabel }(\mathbf{N}=75 ; \alpha=\mathbf{0 , 0 5})=\mathbf{0 , 2 2 7} \\
\end{array}$ & Kesimpulan \\
\hline \multicolumn{4}{|c|}{ 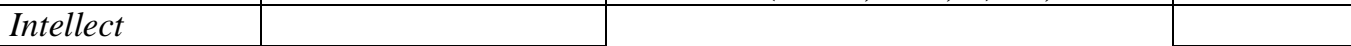 } \\
\hline $\mathrm{Xd} 1.1$ & 0,382 & \multirow{14}{*}{0,227} & Valid \\
\hline $\mathrm{Xd1.2}$ & 0,419 & & Valid \\
\hline $\mathrm{Xd} 1.3$ & 0,362 & & Valid \\
\hline \multicolumn{4}{|l|}{ Ideology } \\
\hline $\mathrm{Xd} 2.1$ & 0,425 & & Valid \\
\hline $\mathrm{Xd} 2.2$ & 0,477 & & Valid \\
\hline $\mathrm{Xd} 2.3$ & 0,320 & & Valid \\
\hline \multicolumn{2}{|l|}{ Public Practice } & & \\
\hline $\mathrm{Xd} 3.1$ & 0,502 & & Valid \\
\hline $\mathrm{Xd3.2}$ & 0,628 & & Valid \\
\hline $\mathrm{Xd} 3.3$ & 0,566 & & Valid \\
\hline \multicolumn{3}{|l|}{ Private Practice } & \\
\hline $\mathrm{Xd} 4.1$ & 0,529 & & Valid \\
\hline $\mathrm{Xd} 4.2$ & 0,649 & & Valid \\
\hline $\mathrm{Xd} 4.3$ & 0,435 & & Valid \\
\hline \multicolumn{4}{|l|}{ Experience } \\
\hline $\mathrm{Xd} 5.1$ & 0,464 & & Valid \\
\hline Xd5.2 & 0,435 & & Valid \\
\hline Xd5.3 & 0,402 & & Valid \\
\hline
\end{tabular}

Sumber: Data Primer, diolah 2018 
Berdasarkan Tabel 5 menunjukkan nilai koefisien korelasi dari untuk dimensi intellect diketahui nilai koefisien korelasi Xd1.1 sebesar 0,382, Xd1.2 sebesar 0,419, dan Xd1.3 sebesar 0,362, dimana nilai koefisien tersebut lebih besar dari nilai $r$ kritis $(0,227)$, artinya semua pertanyaan yang ada pada dimensi intellect adalah pertanyaan yang valid dalam mendukung dimensi intellect. Untuk dimensi ideology untuk Xd2.1 sebesar 0,425, Xd2.2 sebesar 0,477 dan Xd2.3 sebesar 0,320 lebih besar dari $\mathrm{r}$ kritis $(0,227)$, artinya semua pertanyaan yang ada pada dimensi ideology adalah pertanyaan yang akurat atau valid dalam mendukung dimensi ideology.

Selanjutnya untuk dimensi public practice diketahui nilai koefisien korelasi Xd3.1 sebesar 0,502, Xd3.2 sebesar 0,628, dan Xd3.3 sebesar 0,566 , yang mana nilai koefisien tersebut lebih besar dari nilai $\mathrm{r}$ kritis $(0,227)$, artinya semua pertanyaan yang ada pada dimensi public practice adalah pertanyaan yang valid dalam mendukung dimensi public practice. Selanjutnya untuk dimensi private practice diketahui nilai koefisien korelasi Xd4.1 sebesar 0,529, Xd4.2 sebesar 0,649, dan Xd4.3 sebesar 0,435 , yang mana nilai koefisien tersebut lebih besar dari nilai $r$ kritis $(0,227)$, artinya semua pertanyaan pada dimensi private practice merupakan pertanyaan valid dalam mendukung dimensi private practice. Sedangkan untuk dimensi experience diketahui nilai koefisien korelasi Xd5.1 sebesar 0,464, Xd5.2 sebesar 0,435, dan Xd5.3 sebesar 0,402, dimana nilai koefisien tersebut lebih besar dari nilai $r$ kritis $(0,227)$, artinya semua pertanyaan yang ada pada dimensi experience adalah pertanyaan yang valid dalam mendukung dimensi experience.

\section{Gaya}

\section{Transformasional}

Kepemimpinan

Hasil uji validitas untuk variabel gaya kepemimpinan dengan 4 dimensi dan diukur dengan 15 pertanyaan pengukuran yaitu dimensi idealize influence, Inspirational Motivation, Intellectual Stimulation dan Individual Condisertaion, seperti paba Tabel 6 berikut:

Tabel 6

Hasil Uji Validitas Gaya Kepemimpinan Tranformasional

\begin{tabular}{|c|c|c|c|}
\hline Dimensi & $\begin{array}{c}\text { Nilai Koefisien } \\
\text { Korelasi Product } \\
\text { Moment }\end{array}$ & $\begin{array}{l}\text { Nilai Koefisien Korelasi } \\
\text { Product Moment Tabel } \\
(\mathrm{N}=75 ; \alpha=\mathbf{0 , 0 5})=\mathbf{0 , 2 2 7}\end{array}$ & Kesimpulan \\
\hline Idealize Influence & & \multirow{12}{*}{0,227} & \\
\hline Yd1.1 & 0,378 & & Valid \\
\hline Yd1.2 & 0,413 & & Valid \\
\hline Yd1.3 & 0,444 & & Valid \\
\hline \multicolumn{2}{|l|}{ Inspirational Motivation } & & \\
\hline $\mathrm{Yd} 2.1$ & 0,332 & & Valid \\
\hline Yd2.2 & 0,444 & & Valid \\
\hline $\mathrm{Yd} 2.3$ & 0,448 & & Valid \\
\hline \multicolumn{2}{|l|}{ Intellectual Stimulation } & & \\
\hline $\mathrm{Yd} 3.1$ & 0,370 & & Valid \\
\hline Yd3.2 & 0,323 & & Valid \\
\hline $\mathrm{Yd} 3.3$ & 0,368 & & Valid \\
\hline \multicolumn{4}{|l|}{ Individual Condisertaion } \\
\hline $\mathrm{Yd} 4.1$ & 0,420 & & Valid \\
\hline $\mathrm{Yd} 4.2$ & 0,357 & & Valid \\
\hline Yd4.3 & 0,377 & & Valid \\
\hline
\end{tabular}

Sumber: Data Primer, diolah 2018 
Pada Tabel 6 menunjukkan bahwa nilai koefisien korelasi dari dimensi idealize influence untuk Yd1.1 sebesar 0,378, Yd1.2 sebesar 0,413 dan Yd1.3 sebesar 0,444 lebih besar dari r kritis $(0,227)$, artinya semua pertanyaan pada dimensi idealize influence adalah pertanyaan akurat atau valid dalam mendukung dimensi tersebut. Selanjutnya untuk dimensi inspirational motivation diketahui nilai koefisien korelasi Yd2.1 sebesar 0,332, Yd2.2 sebesar 0,444, dan Yd2.3 sebesar 0,448, dimana nilai koefisien tersebut lebih besar dari nilai $r$ kritis $(0,227)$, artinya semua pertanyaan pada dimensi inspirational motivation adalah valid dalam mendukung dimensi tersebut. Pada dimensi intellectual stimulation diketahui nilai koefisien korelasi Yd3.1 sebesar 0,370, Yd3.2 sebesar 0328, dan Yd3.3 sebesar 0,368 , dimana nilai koefisien tersebut lebih besar dari nilai $r$ kritis $(0,227)$, artinya semua pertanyaan pada dimensi intellectual stimulation adalah valid dalam mendukung dimensi tersebut. Sedangkan untuk dimensi individual condisertaion diketahui nilai koefisien korelasi Yd4.1 sebesar 0,420, Yd4.2 sebesar 0,357, dan Yd4.3 sebesar 0,377 , dimana nilai koefisien tersebut lebih besar dari nilai $r$ kritis $(0,227)$, artinya semua pertanyaan dimensi individual condisertaion adalah valid dalam mendukung dimensi tersebut.

\section{Uji Reabilitas}

Tabel 7

Reliabiltas Variabel Penelitian

\begin{tabular}{|l|c|c|c|}
\hline \multicolumn{1}{|c|}{ Variabel } & Cronbach Alpha & Nilai Kritis & Keterangan \\
\hline $\begin{array}{l}\text { Tingkat Religuitas } \\
\text { Gaya Kepemimpinan } \\
\text { Transformasional }\end{array}$ & 0,779 & 0,6000 & Reliabel \\
\hline
\end{tabular}

Sumber : Data Primer, diolah 2018

Pada Tabel 7 menyatakan bahwa nilai cronbach alpha tingkat religuitas sebesar 0,779 dan gaya kepemimpinan transformasional sebesar 0,774 lebih semua variabel adalah reliabel. Hal ini menunjukkan bahwa alat yang digunakan untuk mengukur suatu besar dari nilai kritis $(0,6000)$, artinya

konstruk adalah relevan.

\section{Uji Normalitas}

Tabel 8

Uji Normalitas

\begin{tabular}{|l|l|r|}
\hline \multicolumn{2}{|c|}{} & Unstandardized Residual \\
\hline $\mathrm{N}$ & Mean & 54 \\
\hline \multirow{2}{*}{$\begin{array}{l}\text { Normal } \\
\text { Parameters }\end{array}$} & Std. Deviation & $0 \mathrm{E}-7$ \\
\hline \multirow{2}{*}{$\begin{array}{l}\text { Most Extreme } \\
\text { Differences }\end{array}$} & Absolute &, 32750459 \\
\cline { 2 - 3 } & Positive &, 336 \\
\cline { 2 - 3 } & Negative &,- 336 \\
\hline Kolmogorov-Smirnov Z & 1,472 \\
\hline \multicolumn{2}{|l|}{ Asymp. Sig. (2-tailed) } &, 983 \\
\hline
\end{tabular}

\section{Sumber : Data Primer, diolah 2018}

Berdasarkan hasil uji One-Sample $(0,05)$, dapat disimpulkan bahwa data Kolmogorov-Smirnov test seperti terlihat pada Tabel 9, menunjukkan bahwa nilai asymp. Sig (2-tailed) sebesar 0,983. Karena nilai 0,983 $>\alpha$ berdistribusi normal. Artinya semua variabel independen yang diteliti mempunyai data yang berdistribusi normal. 


\section{Uji Multikolinearitas}

Tabel 9

Uji Multikolinearitas

\begin{tabular}{|l|c|c|}
\hline \multirow{2}{*}{$\begin{array}{c}\text { Variabel } \\
\text { Independen }\end{array}$} & \multicolumn{2}{c|}{ Nilai Collinearity Statistics } \\
\cline { 2 - 3 } & Tolerance & VIF \\
\hline Jenis Kelamin & 0,968 & 1,034 \\
\hline Usia & 0,941 & 1,063 \\
\hline Tingkat Religuitas & 0,912 & 1,096 \\
\hline
\end{tabular}

Berdasarkan hasil uji multikolinearitas seperti pada Tabel 9 mennjukkan bahwa nilai tolerance variabel jenis kelamin sebesar 0,968, usia sebesar 0,941, dan tingkat religuitas sebesar 0,912 , yang mana nilai tolerance tersebut $>0,10$. Selanjuntnya untuk nilai VIF variabel jenis kelamin sebesar 1,034, usia sebesar 1,063, dan tingkat religuitas sebesar 1,096 yang mana nilai VIF tersebut $<10$. Sehingga dapat disimpulkan bahwa variabel yang diteliti tidak mengandung multikolinearitas.

\section{Uji Hetersoskidasitas}

Heterokedastisitas seperti pada Tabel 7 berikut:

Tabel 10

Uji Heterokedastisitas

\begin{tabular}{|l|c|c|}
\hline \multicolumn{1}{|c|}{ Variabel } & Correlation Coefficient & Sig. (2-tailed) \\
\hline Tingkat Religuitas & 0,159 & 0,250 \\
\hline Jenis Kelamin & 0,113 & 0,336 \\
\hline Usia & 0,355 & 0,264 \\
\hline
\end{tabular}

Sumber: Data Primer, diolah 2018

Berdasarkan uji heterokedastisitas seperti terlihat pada Tabel 10, hal ini menunjukkan bahwa nilai signifikan masing-masing variabel yaitu variabel tingkat religuitas sebesar 0,250 , jenis kelamin sebesar 0,336, dan usia sebesar 0,264, yang mana nilai signifikan tersebut $>\alpha(0,05)$. Artinya variabel yang diteliti tidak mengandung unsur heterokedastisitas.

\section{Analisis Uji Hipotesis}

Tabel 11

Hasil Uji Model Regresi

\begin{tabular}{|c|c|c|c|}
\hline Variabel & Koefisien Regresi & T hitung & Signifikan \\
\hline (Constant) & 3,273 & & \\
\hline Tingkat Religuitas & 0,151 & 1,916 & 0,033 \\
\hline Jenis Kelamin & 0,082 & 1,868 & 0,039 \\
\hline Usia & 0,214 & 2,321 & 0,003 \\
\hline R & 0,475 & & \\
\hline R Square & 0,225 & & \\
\hline F hitung & 7,707 & & \\
\hline Signifikan F hitung & 0,000 & & \\
\hline N & 75 & & \\
\hline
\end{tabular}

Sumber: Data Primer, diolah 2018

Berdasarkan Tabel 11 dapat diperoleh model estimasi sebagai berikut ; $\mathrm{GP}=3,273+0,151 \mathrm{TR}+0,082 \mathrm{JK}+0,214 \mathrm{U}$

Model penelitian ini memliki nilai $\mathrm{R}$ Square $\left(\mathrm{R}^{2}\right)$ sebesar 0,225, artinya besarnya tingkat religuitas, usia, dan jenis kelamin terhadap gaya kepemimpinan transformasional sebesar 22,5\%. Hal ini memberi kesimpulan bahwa tidak hanya variabel tingkat religuitas, usia, dan jenis kelamin yang mempengaruhi model 
gaya kepemimpinan transformsional, melainkan ada beberapa variabel lain yang berpengaruh terhadap model gaya kepemimpinan transformasional.

Berdasarkan Tabel 11 dapat diketahui bahwa pada uji parsial masing - masing variabel independen dalam penelitian ini memiliki nilai signifikansi kurang dari 5\% sehingga dapat disimpulkan bahwa setiap variabel independen dalam penelitian ini memliki pengaruh pada varaibel dependen yaitu gaya kepemimpinan.

Berdasarkan Tabel 11 dapat diketahui bahwa secara simultan model yang dihasilkan dapat digunakan sebagai estimator dalam menganalisis faktor yang mempengaruhi gaya kemepmimpinan. Hal ini dapat dilihat dari besarnya uji $\mathrm{F}$ yang memiliki tingkat signifikansi kurang dari 5\%.

Berdasarkan persamaan diatas dapat diketahui bahwa usia memiliki pengaruh yang lebih besar terhadap gaya kepemimpinan. Semakin usia seseorang matang maka semakin bijaksana, memberikan inspiratif dan dapat memberikan porsi lebih besar kepada sub koordinat untuk mengembangkan potensi dirinya.

Kedua adalah tingkat religuitas yang memiliki pengaruh lebih besar kepada gaya kepemimpinan. Hal ini menunjukkan bahwa semaki tinggi tingkat religuitas seseorang dalam hal ini adalah semakin banyak pengalaman spiritual yang dimilikinya maka semakin bijaksana dan supportif terhadap sub ordinat dalam mengembangkan potensi dirinya dalam hal pekerjaan.

Jenis kelamin memiliki pengaruh lebih sedikit. Hal ini menunjukkan apapun jenis kelamin responden, semakin dewasa usia seseorang sehingga pengalaman hidup yang dimiliki semakin bertambah didukung dengan semakin banyak pengalaman spiritual yang dimiliki maka semakin bijaksana, pengertian, dan support terhadap pengembangan potensi diri pada karyawannya.

\section{KESIMPULAN}

Berdasarkan penjelasan diatas, dapat ditarik kesimpulan bahwa (i) terdapat keterkaitan antara tingkat religuitas, usia responden, dan jenis kelamin responden dengan gaya kepemimpinan transformasional. (ii) dalam tingkat religuitas, semakin banyak pengalaman spiritualis seseorang maka semakin tinggi tingkat religuitas seseorang sehingga dalam berkomunikasi lebih mempertahankan aspek menghormati satu sama lain.(iii) kaitan dengan usia responden,semakin tua usia seseorang maka semakin matang pengalaman yang dimiliki, semakin banyak pengetahuan yang dimiliki, semakin bijaksana dalam bersikap sehingga hal tersebut menimbulkan empati dan simpati dari banyak sub koordinat. (iv) kaitan dengan gaya kepemimpinan, kejelasan pemimpin dalam mengkomunikasikan tujuan organisasi, menyakinkan sub ordinat akan pentingnya peran setiap tugas yang diemban merupakan salah satu faktor yang harus di penuhi agar tujuan organisasi dapat tercapai. Kemampuan seperti hal tersebut bisa didapatkan oleh seorang pemimpin seiring dengan pengalaman dan pengetahuan yang dimilikinya. (v) kaitan dengan jenis kelamin, pemimpin pria cenderung lebih berorientasi pada gaya kepemimpinan transformasional.

\section{DAFTAR PUSTAKA}

Aytug Akar. 2010. Transformasional and Transactional Leadership Characteristic of Intercollagiate Athletes and Non Athletes. Thesis. Departement of Physical Education 
and Sport The Middle East Technical University. Tukey.

Barbara Holdcroft. 2006. What is Religiosity?.catholic Education : A Journal of Inquiry and Practice, 10 (1), 89-103.

Belal.A. Kaifi dan Bahaudin. G.Mujtabe. 2010. Transformational Leadership of Afghans and American : A Study of Culture, Age and Gender. J.Sevice Science and Management $3: 150-158$.

Bernard M. Bass. dan Bruce .J.Avolio. 1992. Developing transformational leadership: 1992 and beyond. Journal of European Industrial Training, 14 (5), 21-27 dan 1994.Improving

Organizational Effectiveness Through Transformational Leadership. Sage Publication. 1997. Does The

Transactional-Transformational Leadership Paradigm Transceden Organizational and National Boundaries? American Psychological Association. 52 (2), $130-139$.

Bhargava R. Kotur dan S.Anbazhagan. 2014. The Influence of Age and Gender on the Leadership Style. IOSR Journal of Business and Management $16(1)$. www.iosrjournals.org

Felix,C.O.,A.H.Achmad,R.B. Arshad. 2015. Examing Ethical Reasoning and Transactional Leadership Style in the Nigerian Public Sector.Journal of Humanities and Social Science 20 (6). http://files.ictmmp0.webnode.com/200 0000134c5634d531/UJI VALIDI TAS_DAN_RELIABILITAS.pdf

Josep Hage. 2013. Influence of Religion and Religiousity on Leadership Practice in The Workplace: A Quantitative Correlation Study.Dissertation. Doctor of Business Administration University of Phoenix.Arizona.

Liu,J dan J.A.Wilson.2011. The Impact of Culture and Religion on Leadership and Management Training a Comparison of Three Continents.Jurnal Pengurusan 33:29-36.

Muhammad Nazir. 2013. Metode Penelitian. Ghalia Indonesia. Jakarta.

Odumeru, .James A, Ifeanyi. George. Ogbonna. 2013. Transformational vs Transactional Leadership Theories:Evidence in Literature. International Review of Management and Business Research 2(2); www.irmbrjournal.com Senin, 1 Januari 2018. 18.40 Wib.

Stefan Huber dan Odilo. W.Huber. 2012. The Centrality of Religiosity Scale (CRS). Religion 3.

Stephen P. Robbins dan Timothy A.Judge. 2008. Perilaku Organisasi. Edisi 12. Jilid 2. Salemba Empat.Jakarta.

Umme Salma Sultana, Mohd Ridzuan Darn dan Liu Yao. 2015. Transformational or Transactional Leadership: Which Work Best For Now? International Journal of Industrial Management (IJM). 